\title{
Developmental Factors That Predict Head Movement During Resting-State fMRI in Preschool- Age Children
}

Chelsea A. Johnson

Michigan State University

Emily 0. Garnett

University of Michigan

Ho Ming Chow

University of Delaware

Gregory J. Spray

Michigan State University

David C. Zhu

Michigan State University

Soo-Eun Chang ( $\nabla$ sooeunc@med.umich.edu )

University of Michigan https://orcid.org/0000-0003-4448-9525

Research

Keywords: Temperament, stuttering, fMRI, preschool-age, pediatric MR neuroimaging, sex differences

Posted Date: July 27th, 2021

DOI: https://doi.org/10.21203/rs.3.rs-704477/v1

License: (9) (i) This work is licensed under a Creative Commons Attribution 4.0 International License.

Read Full License 


\section{Abstract}

Background: Early childhood marks a period of dynamic neurocognitive development. The preschool age coincides with the onset of many childhood disorders and is a developmental period that is frequently studied to determine markers of neurodevelopmental disorders. Magnetic resonance imaging (MRI) is often used to explore typical brain development and the neural bases of neurodevelopmental disorders. One advantage of MRI is that it provides comprehensive imaging data with high spatial resolution that is not possible with "child-friendly" techniques such as electroencephalography (EEG) and functional nearinfrared spectroscopy (fNIRS). However, acquiring high-quality MRI data in young children is challenging. The enclosed space and loud sounds can trigger unease and cause excessive head movement. A better understanding of potential factors that predict successful MRI acquisition would increase chances of collecting useable data in children with and without neurodevelopmental disorders.

Methods: We investigated whether age, sex, stuttering status, and childhood temperament as measured using the Child Behavioral Questionnaire, could predict movement extent during resting-state functional MRI (rs-fMRI) in 76 children aged 3 to 7 years, including 42 children who stutter (CWS).

Results: The CWS did not differ significantly from controls in temperament or head movement during scanning. Boys exhibited significantly more movement than girls, and younger age was a consistent predictor of increased movement, unless temperament was considered. Effortful control and negative affectivity significantly predicted movement especially in young boys.

Conclusions: Considering temperament, age, and sex may help predict the success of acquiring useable rs-fMRI data in young children and inform future studies developing better desensitization techniques for pediatric MR neuroimaging.

\section{Research Highlights}

- Temperament, age, sex, and clinical status (stuttering, controls) were examined in relation to the extent of head movement during MRI scanning in preschool-age children.

- Age and sex strongly predicted head movement measured during resting-state fMRI (rs-fMRI) scanning.

- Among temperament variables, effortful control and negative affectivity were significant predictors of head movement during rs-fMRI. These relationships were modulated by sex.

- Having stuttering was not a significant predictor in the extent of head movement during rs-fMRI.

\section{Background}

Though generally considered to be a technique that is difficult to apply in younger populations, MRI has been used at an increasing rate over the last few decades to study brain development in typically developing children and children with neurodevelopmental disorders (1). The onset of many 
neurodevelopmental disorders, such as dyslexia (2-4), attention-deficit/ hyperactivity disorder ([ADHD]; 5), specific language impairment ([SLI]; 6), autism spectrum disorders ([ASD]; 7), intellectual disability (8), and developmental stuttering $(9,10)$ occurs at preschool-age or earlier. The ability to detect subtle neural differences near symptom onset can be greatly enhanced by the acquisition of whole-brain measures using functional magnetic resonance imaging (fMRI), which is crucial to extract both localized and network-level information to expand our understanding of the nature of these neurodevelopmental disorders. Early detection of brain network-level changes associated with childhood neurodevelopmental disorders might pave the way for developing assessments, interventions, and better prognostic markers for these disorders; however, this requires acquiring MRI data from very young children.

Collecting high-quality MRI data from preschool-age children is challenging. Notably, age is an important factor that influences data quality across various data collection methods in terms of compliance, active participation, and reliability of measurement $(11,12)$. For MRI in particular, it is difficult for young children to remain still for the 30 to 60 minute scanning period required for most research scans $(11,12)$. In addition, young children may exhibit fear or anxiety associated with the scanning environment, which can lead to increased movement during scanning. Previous research has shown that for neuroimaging studies in children 4-6 years of age, researchers may need to increase recruitment for data collection by $20-40 \%$ to obtain sufficient useable data without movement artifacts (12). Malisza and colleagues (11) indicated that children 2-3 years of age have a significantly lower rate of successful MRI completion than children 6-7 years of age. These authors also suggest that researchers should anticipate a failure rate of at least $50 \%$ if a study includes children $2-7$ years of age (11). Age is consistently found to influence the "success" of MRI data collection in children. Success of MRI data collection in this study is defined as data that are relatively free of movement artifacts and are thus of sufficient quality to be included in data analysis. In preschool-age children, success rates are especially low $(11,12)$. Given the challenges researchers face in acquiring MRI data in young children, it is vital to understand factors that may interact with the age of the child that could lead to excessive movement during scanning.

Previous research has suggested that scan duration, movement restrictions, being placed within a confined space, and the excessive noise produced by MRI gradient coils may contribute to a child having difficulty completing a scan (13-15). Potential modulatory factors that have been investigated in clinical disorders and typically developing children include age and sex; however, the contribution of these variables is understudied and thus poorly understood $(11,16)$. Some studies have found that age did not predict willingness to participate in MRI but did predict scanning success (11). The sample sizes in this study differed across age groups however, potentially influencing their results. Additionally, 2-5 year-olds had a failure rate of $50 \%$, while $6-7$ year-olds only had a failure rate of $35 \%$. There is no strong evidence for an effect of sex $(11,16)$; however, not all studies explicitly examined sex as a factor (12). These studies importantly did not examine the differences between sexes within clinical populations, despite a large body of evidence suggesting that different behaviors and developmental patterns are present among boys and girls diagnosed with neurodevelopmental disorders (e.g., 17-20). 
Still, some young children seem to be able to tolerate scanning better than much older children. This observation suggests that interactions with variables other than age may predispose some children to tolerate scanning better than others. One such factor that may influence pediatric scanning success is temperament, or one's innate behavioral dispositions. For example, temperament affects a child's tolerance to many clinical environments such as doctor and dental visits (e.g., 21-23). To date, few studies have directly investigated temperament as it relates to the successful completion of MRI scanning in children $(16,24)$. From these studies, the best predictors of movement during scanning were poor attention and adaptability skills (i.e., ability to handle novel experiences) among preschool- and school-age children $(16,24)$. Children with neurodevelopmental disorders may display decreased attention regulation and adaptability, which might further compromise their ability to tolerate scanning (25-33). While some studies have shown that children with neurodevelopmental disorders such as ADHD, and ASD, or developmental delays tend to have fewer successful scans than controls, the reasons for this have not been clarified, especially in preschool-age children $(12,16)$.

Moreover, temperament factors such as adaptability and attentional control develop differently between the sexes, even in typically developing children. Preschool-age girls tend to have more advanced skills related to effortful control than their age-matched male peers (34). If temperamental factors associated with poor attention and adaptability skills influence scanning tolerance in children, those with neurodevelopmental disorders may already be at a greater disadvantage and have a lower probability of success, leading to spurious group differences that may be erroneously attributed to the core clinical condition. If temperament factors that influence MRI scanning develop more slowly in boys than girls, boys with neurodevelopmental disorders may have an even more challenging time tolerating MRI scanning.

Several studies to date have reported that children who stutter (CWS) and children who do not stutter differ in some temperament dimensions. For example, CWS have been shown to demonstrate decreases in inhibition (35-38), attentional shifting $(35,36)$, attentional focusing $(36,37,39)$, and attentional regulation $(36,40)$. They also exhibit increased difficulty adapting to change $(41-42)$, present with greater negative affect $(35,42,43)$, display increased emotional reactivity $(40)$, show higher activity levels $(37,42)$, demonstrate more anger and frustration $(35,39)$, and exhibit more impulsivity $(37)$. Because these factors may contribute to tolerance of the scanning procedures in clinical populations, information that further elucidates relationships between temperament, presence of a clinical condition (in this case, stuttering), and head movement during scanning, could help develop strategies to increase chances of collecting usable MRI data that is comparable across the clinical and control groups.

The current study investigated whether clinical condition (stuttering compared to children who do not stutter, hereafter referred to as "controls"), age, sex, and temperament as assessed by scores on the Child Behavior Questionnaire ([CBQ]; 44), could predict excessive head movement during resting-state fMRI scanning in a cohort of preschool-age children. We focused our temperament analyses on the three CBQ composite scores: effortful control, negative affectivity, and extraversion/surgency. Effortful control reflects a child's ability to control attentional processes and regulate behaviors, such as their ability to 
maintain focus on a task. Negative affectivity measures children's negative emotional responses, such as a negative response to an adverse, unique, or high-intensity event. Extraversion/surgency describes how extroverted or outgoing a child may be, for example, how willing a child may be open to new experiences (45). Guided by previous research reporting temperament differences between CWS and controls as well as the relationship between temperament and MRI tolerance in children, we tested the following hypotheses. First, we expected that CWS would exhibit significantly more movement during scanning than controls. Second, we expected that the groups would differ in temperament indices that may affect tolerance of MRI procedures, including effortful control and negative affectivity, because of their relationship to poor attention and adaptability skills (i.e., ability to handle novel experiences) that have been shown to be associated with increased tolerance of MRI scanning $(16,24)$. These factors are consistent with the effortful control scale on the CBQ that measures self-regulation of behavior and emotions. Our third hypothesis tested whether the extent of movement during MRI scanning is influenced by temperamental characteristics associated with lower adaptability skills and attentional control, such as low effortful control and negative affectivity scores. We predicted that these temperamental differences would be associated with the most movement artifacts in their scans and that this relationship would be modulated by age and sex.

\section{Methods}

\section{Participants}

This current study included 76 participants (42 CWS, 34 controls) from an ongoing longitudinal project examining the neural bases of developmental stuttering (46). MRI data collected from the first visits were used in this study from the larger longitudinal study. Details on recruitment, testing, and in/exclusion criteria for this longitudinal study can be found in Chang \& Zhu (47). Briefly, all children were monolingual English speakers and scored within two standard deviations of the mean on all standardized speechlanguage assessments and intelligence tests. Participants included in this study were those with complete CBQ scores and resting-state fMRI (rs-fMRI) datasets collected. The age range of participants was 37-86 months ( $3-7$ years) at the time of scanning $(M=57.99, S D=14.03)$. See Table 1 for participant demographics.

All study procedures were approved by the Institutional Review Board at Michigan State University's in accordance with the Declaration of Helsinki. Informed consent/assent was obtained from all children and their parents before participation. Children were given small prizes and stickers for participation and received nominal remuneration.

\section{Behavioral Testing}

\section{Speech and language testing}


All children completed a battery of cognitive and speech-language assessments, as detailed in Chang \& Zhu (47). Briefly, these tests included the Clinical Evaluation of Language Fundamentals Preschool-2 ([CELF-P2]; 48) or Clinical Evaluation of Language Fundamentals-5 ([CELF-5]; 49), the Goldman-Fristoe Test of Articulation-2 [GFTA-2] (50), and the Wechsler Scales of Intelligence for the participants' appropriate age group $(51,52)$. Regardless of group, all children scored within the typical range for their age on these standardized assessments. Consistent with previous studies, a child was considered to be stuttering if they met the following criteria: 1) three or more stuttering-like disfluencies per 100 syllables, 2) a diagnosis of 'very mild' or greater based on the index score from the Stuttering Severity Instrument ([SSI-4]; 53) during a narrative story-telling task and a conversation sample collected with a certified speech-language pathologist (54), and 3) expressed concern from parent and clinician impression consistent with stuttering diagnosis.

\section{Measures of temperament}

Parents completed the 94-item CBQ (44), which assesses the child's temperament within the previous 6 months. This questionnaire uses a 6-point Likert scale to evaluate children between the ages of 3-6 years. Responses to each of the 94 questions are then grouped to form 15 subscales, including activity level, anger/frustration, approach, attentional focusing, discomfort, falling reactivity and soothability, fear, high-intensity pleasure, impulsivity, inhibitory control, low-intensity pleasure, perceptual sensitivity, sadness, shyness, and smiling and laughter (for a description of each variable, see 44). These aforementioned subscales are used to calculate three $\mathrm{CBQ}$ composite scores were calculated: effortful control, negative affectivity, and extraversion/surgency. These measures were used in the statistical analyses described below.

\section{MRI data acquisition and head motion measures}

Before the MRI visit, all children underwent an MRI training protocol that involved desensitization to the sights and sounds of the scanner environment using games and by visiting a mock MRI scanner. An MRI training protocol that was developed and tested for young children as reported in Theys et al. (55) was implemented to ensure that all children were ready and willing to participate in the subsequent MRI scanning session. On the day of the MRI scan, a trained clinician or graduate student sat next to the child at all times during the scanning session to monitor the child for excessive movement or distress, at which point scanning was stopped and restarted as tolerated. All scans were acquired using a 3T GE Signa HDx MR scanner (GE Healthcare) with an 8-channel head coil in the Department of Radiology at Michigan State University. Each scan session included a 10-minute rs-fMRI scan, which generally occurred after the structural MRI (3D IRFSPGR) and diffusion tensor imaging (DTI) scans (45 minutes total). The rs-fMRI images were collected with echo-planar imaging using the following parameters: 38 contiguous 3-mm axial slices in an interleaved order, echo time $=27.7 \mathrm{~ms}$, repetition time $=2500 \mathrm{~ms}$, flip angle $=80^{\circ}$, field of view $=22 \mathrm{~cm}$, matrix size $=64 \times 64$, ramp sampling, with the first four data points discarded, and each volume of slices acquired 164 times (47). Each rs-fMRI scan was co-registered to the first volume using rigid body rotation. The movement parameters obtained in the co-registration step were used to calculate the frame-wise displacement (FD), an estimate of volume to volume head movement (56) using AFNI's 
1d_tool.py and 1deval. For each participant, the percentage of volumes with FD $>0.5 \mathrm{~mm}$ was used to determinate the degree of excessive head motion.

\section{Data analysis}

\section{Between-group differences}

All statistical analyses were run using IBM SPSS Statistics, version 26. We first used separate independent samples t-tests to compare differences between CWS and controls in (a) movement during rs-fMRI scanning and the three CBQ composite scores: (b) effortful control, (c) negative affectivity, and (d) surgency. The effortful control variable did not meet the assumption of homogeneity of variances, as tested by Levene's Test for Equality of Variances $(F=10.77, p=.001)$, so a Mann-Whitney U test was used to compare CWS and controls for this variable.

\section{Regression analyses}

A linear regression analysis was used to further examine group differences in movement during rs-fMRI scans with age and sex entered as covariates. Due to stuttering status being a nonsignificant predictor in this model (Table 2) and the lack of difference in movement in children who stutter and controls (Table 1), the two groups were collapsed for the subsequent analyses. First, a linear regression assessed the effect of age and sex on head movement during rs-fMRI (Table 3). Additionally, three separate linear regression analyses were conducted to assess the effects of each of the three temperament variables as well as age and sex on head movement during rs-fMRI scanning (Tables 4-6). Lastly, regression models that examined the effects of temperament were conducted separately in girls and boys (Table 7). Individual movement data were transformed using a square root transformation due to not meeting normality of residuals for all regression analyses. All movement analyses were performed using the transformed data.

\section{Results}

\section{Between-group differences}

Children who stutter and controls did not differ significantly in age, socioeconomic status, movement during rs-fMRI scanning, negative affectivity, surgency, or effortful control (Table 1). Multiple linear regression was used to examine the effects of age, sex, stuttering status, and their interactions on head movements. Age and sex were both significant predictors of head movement (Table 2). Age was negatively associated with head movement; not surprisingly, older children tended to move less than their younger peers. Boys tended to have more volumes with significant movement than girls in this model. However, stuttering status (i.e., group) was not significantly associated with head movement, even when accounting for age and sex. Therefore, data from the two groups of children were combined for subsequent analyses. 
Table 1

Demographic information of children who stutter (CWS) and controls included in this study.

\begin{tabular}{|c|c|c|c|c|c|c|}
\hline & \multicolumn{2}{|c|}{$\begin{array}{l}\text { CWS, n = } 42 \text { (15 } \\
\text { Girls) }\end{array}$} & \multicolumn{2}{|c|}{$\begin{array}{l}\text { Controls, n = } 34 \text { (19 } \\
\text { Girls) }\end{array}$} & \multicolumn{2}{|c|}{$\begin{array}{l}\text { Between Group } \\
\text { Comparisons }\end{array}$} \\
\hline & $\begin{array}{l}\text { Mean } \\
(S D)\end{array}$ & Range & $\begin{array}{l}\text { Mean } \\
(S D)\end{array}$ & Range & $t$ & $p$ \\
\hline Age (months) & $\begin{array}{l}59.09 \\
(14.89)\end{array}$ & $38-86$ & $\begin{array}{l}57.10 \\
(13.50)\end{array}$ & $37-83$ & -.611 & .543 \\
\hline Socioeconomic status ${ }^{a}$ & $\begin{array}{l}6.12 \\
(.769)\end{array}$ & $5-7$ & $6(.975)$ & $4-7$ & -.571 & .570 \\
\hline $\begin{array}{l}\text { Head movement during } \\
\text { scanning }\end{array}$ & $\begin{array}{l}29.60 \\
(27.08)\end{array}$ & $0-93$ & $\begin{array}{l}28.95 \\
(24.00)\end{array}$ & $0-84.14$ & -.112 & .911 \\
\hline Negative affectivity & $3.73(.71)$ & $\begin{array}{l}1.83- \\
5.12\end{array}$ & $3.93(.74)$ & $\begin{array}{l}2.22- \\
5.32\end{array}$ & 1.185 & .242 \\
\hline Surgency & $4.64(.70)$ & $\begin{array}{l}2.52- \\
6.05\end{array}$ & $4.87(.75)$ & $\begin{array}{l}3.13- \\
6.36\end{array}$ & 1.354 & .180 \\
\hline Effortful control & $5.23(.47)$ & $\begin{array}{l}4.22- \\
6.11\end{array}$ & $5.11(.73)$ & $\begin{array}{l}3.37- \\
6.79\end{array}$ & $645.0^{c}$ & .471 \\
\hline \multicolumn{7}{|l|}{ *Significant at $p<.05$} \\
\hline \multicolumn{7}{|l|}{${ }^{a}$ Maternal education level } \\
\hline \multicolumn{7}{|c|}{ b Percentage of volumes with FD $>0.5 \mathrm{~mm}$} \\
\hline
\end{tabular}


Table 2

The effects of sex, age, clinical status (stuttering, control) and their interactions on head movement.

\begin{tabular}{|clllll|}
\hline & Effect & B & SE & t & p \\
\hline Movement & Intercept & 3.779 & 0.543 & 6.959 & $<0.001^{*}$ \\
\cline { 2 - 6 } & Sex & 1.836 & 0.735 & 2.498 & $0.015^{*}$ \\
\cline { 2 - 6 } & Age & -0.071 & 0.034 & -2.108 & $0.039 *$ \\
\cline { 2 - 6 } & Group & 0.936 & 0.831 & 1.127 & 0.264 \\
\hline & Sex*Age & 0.026 & 0.039 & 0.660 & 0.511 \\
\hline Age*Group & -0.013 & 0.039 & -0.336 & 0.738 \\
\hline *Sex*Group & -1.642 & 1.113 & -1.475 & 0.145 \\
\hline
\end{tabular}

\section{Relationship between head movement, age, and sex}

Multiple linear regression examined the effects of age, sex, and their interactions on head movement. The regression equation was significant $(F(3)=5.43, p=.002)$, with an $\mathrm{R}^{2}$ of .185. Both age and sex were significant predictors of head movement in the model (Table 3 ). Age was negatively associated with head movement in our model. Boys had more volumes with significant movement than girls in the study.

Table 3

The effects of age, sex, and their interactions on head movement.

\begin{tabular}{|llllll|}
\hline & Effect & B & SE & t & P \\
\hline \multirow{3}{*}{ Movement } & Intercept & 4.170 & 0.406 & 10.267 & $0.000^{*}$ \\
\cline { 2 - 6 } & Age*Sex & 0.021 & 0.039 & 0.535 & 0.594 \\
\cline { 2 - 6 } & Sex & 1.124 & 0.546 & 2.058 & $0.043^{*}$ \\
\cline { 2 - 6 } & Age & -0.072 & 0.028 & -2.623 & $0.011^{*}$ \\
\hline *Significant at $\mathrm{p}<.05$ & & & & \\
\hline
\end{tabular}

\section{Relationship between temperament and head movement}

Three separate multiple linear regression analyses were conducted to examine whether the three CBQ composite variables (surgency, effortful control, negative affectivity) predicted head movement. Each 
regression model included five predictors: main effect of the $C B Q$ variable, sex, age, the interaction between age and the $\mathrm{CBQ}$ variable, and the interaction between sex and the CBQ measure (Tables 4-6, Figs. 1-2). The three-way interaction between age, sex, and CBQ variable was not included because the interaction between age and sex was not significant in the analysis presented in Table 2 . The first model examined the $\mathrm{CBQ}$ variable surgency. The overall model was significant $\left(F(5)=3.250, p=.011, R^{2}=.188\right.$ ); however, none of the predictors were significant (Table 4). The second model examining the effect of effortful control was significant $\left(F(5)=4.691, p=.001, R^{2}=.251\right)$. Effortful control, sex, and the interaction between sex and effortful control were the significant predictors of movement in the model (Table 5). The significant interaction term between effortful control and sex indicates that the relationship between effortful control and movement extent varies by the sex of the child; therefore, two additional regressions models were run, separately in boys and girls. These analyses showed that there was a significant negative correlation between effortful control and head movement in boys, but not in girls (Table 7; Fig. 1). The third model predicting movement based on negative affectivity was also significant $\left(F(5)=4.459, p=.001, R^{2}=.242\right)$. While sex alone was not a good predictor of movement, negative affectivity and its interaction with sex were significant predictors of movement (Table 6). Separate analyses for boys and girls showed that negative affectivity did not predict more head movement in either sex (Table 7; Fig. 2).

Table 4

Regression results examining effects of Surgency, Age, and Sex and interactions between Sex*Surgency and Age*Surgency.

\begin{tabular}{|llllll|}
\hline & Effect & B & SE & t & P \\
\hline Movement & Intercept & 5.528 & 2.344 & 2.358 & $0.021^{*}$ \\
\cline { 2 - 6 } & Surgency & -0.056 & 0.475 & -0.118 & 0.907 \\
\cline { 2 - 6 } & Age & 0.028 & 0.124 & 0.228 & 0.821 \\
\cline { 2 - 6 } & Sex & -1.474 & 3.838 & -0.384 & 0.702 \\
\hline & Sex*Surgency & 0.087 & 0.805 & 0.109 & 0.914 \\
\hline *Significant at $p<.05$ & -0.019 & 0.026 & -0.737 & 0.464 \\
\hline
\end{tabular}


Table 5

Regression results examining effects of Effortful Control, Age, Sex, and interactions.

\begin{tabular}{|llllll|}
\hline \multirow{2}{*}{ Movement } & Effect & B & SE & t & p \\
\cline { 2 - 6 } & Intercept & 11.612 & 2.659 & 4.368 & $0.000^{*}$ \\
\cline { 2 - 6 } & Effortful Control & -1.263 & 0.526 & -2.403 & $0.019 *$ \\
\cline { 2 - 6 } & Age & -0.043 & 0.153 & -0.280 & 0.780 \\
\cline { 2 - 6 } & Sex & -11.290 & 5.179 & -2.180 & $0.033^{*}$ \\
\hline & Sex*Effortful Control & 1.980 & 0.983 & 2.015 & $0.048^{*}$ \\
\hline & Age*Effortful Control & -0.004 & 0.029 & -0.153 & 0.879 \\
\hline *Significant at $\mathrm{p}<.05$ & & & & \\
\hline
\end{tabular}

Table 6

Regression results examining effects of Negative Affectivity, Age, Sex, and interactions.

\begin{tabular}{|llllll|}
\hline \multirow{3}{*}{ Movement } & Effect & B & SE & t & p \\
\cline { 2 - 6 } & Intercept & 1.414 & 1.963 & 0.720 & 0.474 \\
\cline { 2 - 6 } & Negative Affectivity & 0.986 & 0.493 & 1.999 & 0.050 * \\
\cline { 2 - 6 } & Age & -0.135 & 0.118 & -1.137 & 0.260 \\
\cline { 2 - 6 } & Sex & 5.538 & 2.988 & 1.853 & 0.068 \\
\hline & Sex*Negative Affectivity & -1.716 & 0.760 & -2.258 & $0.027 *$ \\
\hline ASignificant at $p<.05$ & 0.017 & 0.030 & 0.563 & 0.576 \\
\hline
\end{tabular}


Table 7

Regression results examining effects of age and temperament in boys and girls.

\begin{tabular}{|c|c|c|c|c|c|c|c|c|c|}
\hline & & Girls & & & & Boys & & & \\
\hline & Effect & B & SE & $t(31)$ & $\mathrm{p}$ & B & SE & $\mathrm{t}(39)$ & $\mathrm{p}$ \\
\hline \multirow[t]{3}{*}{ Movement } & (intercept) & 11.06 & 2.61 & 4.24 & $<.001 *$ & 5.53 & 2.23 & 2.47 & $0.018^{*}$ \\
\hline & $\begin{array}{l}\text { Negative } \\
\text { affectivity }\end{array}$ & -0.70 & 0.54 & -1.30 & 0.203 & 0.91 & 0.51 & 1.78 & 0.082 \\
\hline & Age & -0.07 & 0.02 & -2.81 & $0.008^{*}$ & -0.06 & 0.029 & -2.26 & $0.029 *$ \\
\hline \multirow[t]{3}{*}{ Movement } & (intercept) & 8.09 & 2.95 & 2.73 & $0.010 *$ & 8.83 & 3.03 & 2.91 & $0.006^{*}$ \\
\hline & Surgency & 0.06 & 0.62 & 0.11 & 0.913 & -0.10 & 0.48 & -0.21 & 0.829 \\
\hline & Age & -0.07 & 0.02 & -2.66 & $0.012^{\star}$ & -0.05 & 0.02 & -1.80 & 0.079 \\
\hline \multirow[t]{3}{*}{ Movement } & (intercept) & 4.66 & 4.24 & 1.09 & 0.281 & 14.79 & 3.21 & 4.60 & $<.001 *$ \\
\hline & $\begin{array}{l}\text { Effortful } \\
\text { control }\end{array}$ & 0.73 & 0.77 & 0.94 & 0.353 & -1.24 & 0.53 & -2.32 & $0.025^{\star}$ \\
\hline & Age & -0.07 & 0.02 & -2.88 & $0.007 *$ & -0.05 & 0.02 & -2.08 & $0.043^{*}$ \\
\hline
\end{tabular}

\section{Discussion}

The present study examined the effects of clinical group (stuttering status), age, sex, and temperament on the extent of head movement during resting-state functional magnetic resonance imaging (rs-fMRI) scanning in preschool-age children. We predicted that children who stutter (CWS) would exhibit more movement during scanning than the control group, as measured by percent of total MRI volumes that contained head movement exceeding $0.5 \mathrm{~mm}$. Instead, results indicated no significant difference between the two groups of children (Table 1). Furthermore, CWS did not differ significantly from the control group on any of the temperament composite measures indexing negative affectivity, surgency, or effortful control.

Based on previous findings from studies that examined movement during MRI in children (e.g., 11-12), we predicted that effortful control and negative affectivity would be associated with movement during rsfMRI. CWS did not differ from controls in any temperament score measured by the CBQ, and stuttering status was not a significant predictor of movement (Tables 1,2). Hence, we collapsed the groups for our subsequent analyses examining the predictive effect of temperament on movement. We found that two of the CBQ variables - effortful control and negative affectivity - significantly predicted head movement from these analyses. 
Both effortful control and negative affectivity had significant sex*temperament interactions, suggesting that the effect of both effortful control and negative affectivity on movement is different in boys and girls (Tables 5-6). For example, while examining temperament in separate models for boys and girls, a significant negative correlation between effortful control and movement was observed for boys but not in girls (Table 7, Fig. 1). Boys with higher effortful control scores, reflecting better regulation of attentional resources during scanning, moved less during rs-fMRI procedures. Alternatively, boys who showed higher negative affectivity showed a trend of greater movement.

One possible explanation for the disparate relationship between effortful control and head movement among the two sexes in this study is that effortful control matures at different rates in boys compared to girls (for a discussion, see 64). Boys tend to have a more protracted developmental trajectory for effortful control than girls (e.g., 65-67). The difference of maturity rates in some effortful control skills between boys and girls in this study may have influenced the different relationship between effortful control and head movement. Additionally, another possible explanation for the pattern of difference between sexes is that effortful control mediates the development of externalizing behavior in boys but not girls (e.g., 68). These previous findings may explain the observed significant relationship between effortful control and movement in boys but not girls in this study. For example, girls may be able to comply with rs-fMRI procedures regardless of their effortful control scores.

While negative affectivity was a significant predictor of movement and sex modulated this relationship (Table 6), it was not a significant predictor of movement for either boys or girls when they were examined separately (Table 7). The data show a trend for more movement in boys with higher negative affectivity scores (Table 7; Fig. 2). This result suggests that boys who generally experience higher levels of negative affectivity were less able to tolerate scanning. Additionally, the significant interaction between sex and negative affectivity suggests that the relationship between negative affectivity and movement in girls is different from that of boys (Table 6). Negative affectivity is related to feelings of distress during unique or high-intensity experiences. Higher CBQ negative affectivity scores in children in this study could indicate a higher negative response to the novelty of the scanning environment, which may have, in turn, translated into increased movement. Previous studies have found that higher levels of negative affectivity in childhood are associated with more externalizing problems, such as behaviors that are seen as disruptive or problematic, in childhood and later in development as teenagers $(69,70)$.

Our finding that CWS do not differ significantly from controls on temperament scores as measured by the $\mathrm{CBQ}$ was somewhat surprising. While previous research reported differences between CWS and their control peers on various tasks or instruments that measure temperament (for a review, see 57), other studies have failed to find differences between these groups (58-61). It is important to note that the studies of temperament in CWS vary greatly in their methods of sampling (e.g., the children recruited through a clinic vs. from a community sample), age range, and as pointed out by Alm (62), sample sizes as well as the specific test to measure temperamental differences. Many studies recruit CWS from speech and language clinics (e.g., 35, 38, 40, 41) and would have included children currently undergoing therapy, who may be more likely to present with comorbid clinical disorders such as attention deficit hyperactivity 
disorder, language delays, and affective disorders. In addition, preschool age CWS who seek therapy may exhibit higher negative reactions to stuttering than those who do not seek treatment for their stuttering. Thus, CWS who are recruited primarily from clinics have a higher likelihood of differing in temperament measures relative to those that do not seek treatment. Currently, it is difficult to compare the results of this study to others that collected data from older and/or wider age ranges $(35,38,39)$ or studies using different temperament measurements than the CBQ used in this study $(38,40,41,43,63)$. More studies are needed to confirm whether temperament factors differ between CWS and controls, taking into account varied methods of sampling procedures.

Although findings from the current study were based on rs-fMRI data quality, they can be generalized to brain MRI in general. These findings have important implications for conducting MRI research in clinical populations. Previously it has been reported that clinical pediatric populations exhibit more head movement during scanning than controls. This pattern was not observed for the CWS in our study, who did not exhibit significant differences relative to control children in terms of head movement during rsfMRI. Age, sex, effortful control, and negative affectivity were the factors found to be significantly associated with head movement during rs-fMRI in our study. This result suggests that some clinical populations, including children who stutter, may exhibit comparable tolerance to rs-fMRI procedures to their peers.

Further research is needed to better understand what factors may allow one clinical group to tolerate scanning compared to their peers. Children with autism often exhibit heightened sensitivity to their environment, especially for visual and auditory stimuli (for a discussion, see 71), which may predispose this group to have more difficulties tolerating the loud sounds of the MRI machine and restrictions to movement. Results from the present study suggest that exploring other factors like temperament is valuable, as characteristics associated with developmental disorders are heterogeneous even within the same diagnostic category. For example, effortful control has been connected to a lower prevalence of behaviors affiliated with autism (e.g., 27). More research is needed to understand which behavioral characteristics, including temperament, may predict scanning success across different neurodevelopmental disorders.

Findings from our study corroborate previous reports that have emphasized the importance of allowing young children to desensitize to the sights, sounds, and MRI environment. While several previous studies have indicated that the introduction of mock MRI practice sessions before the experimental session may significantly reduce potential movement and data loss during MRI scanning $(55,72-75)$, few have examined how individual differences within pediatric populations may need to be considered when designing MRI desensitization interventions. It is essential to consider what steps researchers and clinicians can take to ensure the comfort of children and the chances of successful data collection carefully based on the needs of the child. Considering how individualized factors may influence a child, such as their age, sex, and temperament, may help those scanning pediatric populations decide what kind of intervention may be needed. 


\section{Limitations}

The data from this study were collected from a longitudinal study of developmental stuttering. These results may be less generalizable to children scanned for purely clinical purposes. For example, our study participants may have certain temperamental characteristics associated with willingness to volunteer in a research study, and in an MRI study in particular. Therefore, due to self-selection, our study may be most relevant to research environments where children volunteer to participate. Future studies involving larger sample sizes, as well as diversity in the pediatric neurodevelopmental populations explored in the study, are necessary to replicate and expand the findings reported in this study and understand how different conditions may predispose children to tolerate rs-fMRI scanning or not.

Our interpretation of how temperament affects movement during scanning is discussed within the context of previous research that explored disruptive externalizing behaviors, such as those that would get a child in trouble at school or warrant psychological evaluation and intervention. These conditions are quite different from the strict procedures involved in rs-fMRI scanning, which can be challenging even for adults. In this study, excessive movement was defined by volumes that contained movement greater than $0.5 \mathrm{~mm}$. This value was chosen as a stringent movement parameter; however, research teams may be able to accept more or less movement depending on their analyses. This stringent threshold leaves a very small margin for error for these participants. Therefore, an inability to comply with these procedures should not be compared to behaviors of clinical significance or any typical behaviors that may be disruptive to everyday life.

\section{Conclusions}

We found that in a sample of young children (3-7 years) who underwent rs-fMRI scanning for research purposes, the best potential predictors of head movement during scanning were age, sex, and the temperament factors effortful control and negative affectivity. If temperament is used as a predictor of rsfMRI tolerance, or MRI in general, in young children, researchers should also consider each temperamental factor differently depending on the sex of the child in their study. Results from this study suggest that assessing temperament may help identify children who could benefit from additional time to desensitize to the MRI environment and scanning procedures. Ultimately, this may lead to improved quality and increased quantity of useable brain scans acquired from young children, which is crucial to furthering our understanding of brain development in children with and without neurodevelopmental disorders.

\section{List Of Abbreviations}

ADHD Attention-Deficit/ Hyperactivity Disorder

ASD Autism Spectrum Disorder

CBQ Child Behavior Questionnaire 
CELF-5 Clinical Evaluation of Language Fundamentals-5

CELF-P2 Clinical Evaluation of Language Fundamentals Preschool-2

CWS Children who Stutter

DTI Diffusion Tensor Imaging

EEG Electroencephalography

FD Frame-Wise Displacement

fNIRS Functional Near-Infrared Spectroscopy

MRI Magnetic Resonance Imaging

rs-fMRI Resting-State Functional Magnetic Resonance Imaging

SLI Specific Language Impairment

\section{Declarations}

\section{Ethics approval and consent to participate}

All study procedures were approved by Michigan State University's Institutional Review Board in accordance with the Declaration of Helsinki. Informed consent/assent was obtained from all children and their parents before participation.

\section{Consent for publication}

Not applicable

\section{Availability of data and material (data transparency)}

The datasets analyzed for this research are available upon reasonable written request and through data agreement.

\section{Competing interests}

The authors declare that they have no competing interests

\section{Funding}

This research was supported by the National Institute on Deafness and Other Communication Disorders grant R01DC011277 (PI Chang)

\section{Authors' contributions}


Conceptualization: Chelsea A. Johnson, Gregory Spray, Soo-Eun Chang, Ho-Ming Chow; Methodology: HoMing Chow, Soo-Eun Chang, Emily O. Garnett, Chelsea A. Johnson, Gregory Spray, David Zhu; Formal analysis and investigation: Ho-Ming Chow, Emily O. Garnett, Chelsea A. Johnson; Writing - original draft preparation: Chelsea A. Johnson, Soo-Eun Chang, Emily O. Garnett; Writing - review and editing: Ho-Ming Chow, Soo-Eun Chang, Emily O. Garnett, David Zhu, Chelsea A. Johnson, Gregory Spray; Funding acquisition: Soo-Eun Chang; Supervision: Soo-Eun Chang, Emily O. Garnett, Ho Ming Chow.

\section{Acknowledgements}

The authors wish to thank all of the children and families that participated in this study. We also thank Saralyn Rubsam, Megan Sheppard, and Nasreen Al-Qadi for their help with recruitment of participants, behavioral testing, and help collecting MRI data, Scarlett Doyle for assisting with MRI data collection, and Ashley Diener for her assistance in speech data analyses.

\section{References}

1. Price CJ. A review and synthesis of the first 20years of PET and fMRI studies of heard speech, spoken language and reading. Neurolmage. 2012 Aug 15;62(2):816-47.

2. Cao F, Yan X, Spray GJ, Liu Y, Deng Y. Brain Mechanisms Underlying Visuo-Orthographic Deficits in Children With Developmental Dyslexia. Front Hum Neurosci [Internet]. 2018 [cited 2018 Dec 9];12. Available from: https://www.frontiersin.org/articles/10.3389/fnhum.2018.00490/full.

3. Raschle NM, Chang M, Gaab N. Structural brain alterations associated with dyslexia predate reading onset. Neurolmage. 2011 Aug;57(3):742-9.

4. Wang Z, Yan X, Liu Y, Spray GJ, Deng Y, Cao F. Structural and functional abnormality of the putamen in children with developmental dyslexia. Neuropsychologia [Internet]. 2018 Jul [cited 2018 Jul 26]; Available from: https://linkinghub.elsevier.com/retrieve/pii/S0028393218303257.

5. Kieling R, Rohde LA. ADHD in Children and Adults: Diagnosis and Prognosis. In: Stanford C, Tannock R, editors. Behavioral Neuroscience of Attention Deficit Hyperactivity Disorder and Its Treatment [Internet]. Berlin, Heidelberg: Springer Berlin Heidelberg; 2010 [cited 2018 Nov 30]. p. 1-16. Available from: http://link.springer.com/10.1007/7854_2010_115.

6. Vydrova R, Komarek V, Sanda J, Sterbova K, Jahodova A, Maulisova A, et al. Structural alterations of the language connectome in children with specific language impairment. Brain Lang. 2015 Dec;1:151:35-41.

7. Joseph RM, Fricker Z, Fenoglio A, Lindgren KA, Knaus TA, Tager-Flusberg H. Structural asymmetries of language-related gray and white matter and their relationship to language function in young children with ASD. Brain Imaging Behav. 2014 Mar;8(1):60-72.

8. Jacola LM, Byars AW, Hickey F, Vannest J, Holland SK, Schapiro MB. Functional magnetic resonance imaging of story listening in adolescents and young adults with Down syndrome: evidence for atypical neurodevelopment. J Intellect Disabil Res. 2014 Oct 1;58(10):892-902. 
9. Bloodstein O, Bernstein Ratner N. A Handbook on Stuttering. 6th ed. New York: Thomson Delmar Learning; 2008.

10. Yairi E, Ambrose N. Epidemiology of stuttering: 21 st century advances. J Fluen Disord. 2013 Jun 1;38(2):66-87.

11. Malisza KL, Martin T, Shiloff D, Yu DCT. Reactions of young children to the MRI scanner environment. Magn Reson Med. 2010;64(2):377-81.

12. Yerys BE, Jankowski KF, Shook D, Rosenberger LR, Barnes KA, Berl MM, et al. The fMRI success rate of children and adolescents: Typical development, epilepsy, attention deficit/hyperactivity disorder, and autism spectrum disorders. Hum Brain Mapp. 2009;30(10):3426-35.

13. Marshall SP, Smith MS, Weinberger E. Perceived Anxiety of Pediatric Patients to Magnetic Resonance. Clin Pediatr (Phila). 1995 Jan 1;34(1):59-60.

14. Tyc VL, Fairclough D, Fletcher B, Leigh L, Mulhern RK. Children's Distress During magnetic Resonance Imaging Procedures. Child Health Care. 1995 Jan;24(1):5-19.

15. Tyc VL, Leigh L, Mulhern RK, Srivastava DK, Bruce D. Evaluation of a Cognitive-Behavioral Intervention for Reducing Distress in Pediatric Cancer Patients Undergoing Magnetic Resonance Imaging Procedures. Int J Rehabil Health. 1997 Oct 1;3(4):267-79.

16. Cahoon GD, Davison TE. Prediction of compliance with MRI procedures among children of ages 3 years to 12 years. Pediatr Radiol. 2014 Oct 1;44(10):1302-9.

17. Arnett $A B$, MacDonald $B$, Pennington BF. Cognitive and behavioral indicators of ADHD symptoms prior to school age. J Child Psychol Psychiatry. 2013;54(12):1284-94.

18. Gaub M, Carlson CL. Gender Differences in ADHD: A Meta-Analysis and Critical Review. J Am Acad Child Adolesc Psychiatry. 1997;36(8):1036-45.

19. Hartley SL, Sikora DM. Sex Differences in Autism Spectrum Disorder: An Examination of Developmental Functioning, Autistic Symptoms, and Coexisting Behavior Problems in Toddlers. J Autism Dev Disord. 2009 Dec;39(12):1715-22.

20. Mandy W, Chilvers R, Chowdhury U, Salter G, Seigal A, Skuse D. Sex Differences in Autism Spectrum Disorder: Evidence from a Large Sample of Children and Adolescents. J Autism Dev Disord. 2012 Jul 1;42(7):1304-13.

21. Berge M ten, Veerkamp JSJ, Hoogstraten J, Prins PJM. Behavioural and emotional problems in children referred to a centre for special dental care. Community Dent Oral Epidemiol. 1999;27(3):181-6.

22. Klingberg G, Broberg AG. Temperament and child dental fear. Pediatr Dent. 1998;20:237-43.

23. Pate JT, Blount RL, Cohen LL, Smith AJ. Childhood medical experience and temperament as predictors of adult functioning in medical situations. Child Health Care. 1996;25(4):281-98.

24. Voepel-Lewis T, Malviya S, Prochaska G, Tait AR. Sedation failures in children undergoing MRI and CT: is temperament a factor? Pediatr Anesth. 2000;10(3):319-23. 
25. Cho S-C, Hwang J-W, Lyoo I-K, Yoo H-J, Kin B-N, Kim J-W. Patterns of temperament and character in a clinical sample of Korean children with attention-deficit hyperactivity disorder. Psychiatry Clin Neurosci. 2008 Apr;62(2):160-6.

26. Hepburn SL, Stone WL. Using Carey Temperament Scales to assess behavioral style in children with autism spectrum disorders. J Autism Dev Disord. 2006 Jul;36(5):637-42.

27. Konstantareas MM, Stewart K. Affect Regulation and Temperament in Children with Autism Spectrum Disorder. J Autism Dev Disord. 2006 Feb;36(2)(1):143-54.

28. Lufi D, Parish-Plass J. Personality assessment of children with attention deficit hyperactivity disorder. J Clin Psychol. 1995 Jan;51(1):94-9.

29. Mclntosh DE, Cole-Love AS. Profile Comparisons between ADHD and Non-ADHD Children on the Temperament Assessment Battery for Children. J Psychoeduc Assess. 1996 Dec 1;14(4):362-72.

30. Melegari MG, Nanni V, Lucidi F, Russo PM, Donfrancesco R, Cloninger CR. Temperamental and character profiles of preschool children with ODD, ADHD, and anxiety disorders. Compr Psychiatry. 2015 Apr 1;58:94-101.

31. Tillman R, Geller B, Craney JL, Bolhofner K, Williams M, Zimerman B, et al. Temperament and Character Factors in a Prepubertal and Early Adolescent Bipolar Disorder Phenotype Compared to Attention Deficit Hyperactive and Normal Controls. J Child Adolesc Psychopharmacol. 2003 Dec;13(4):531-43.

32. White JD. Review Personality, temperament and ADHD:: a review of the literature. Personal Individ Differ. 1999 Oct 1;27(4):589-98.

33. Yoo HJ, Kim M, Ha JH, Chung A, Sim ME, Kim SJ, et al. Biogenetic Temperament and Character and Attention Deficit Hyperactivity Disorder in Korean Children. Psychopathol Basel. 2006 Jan;39(1):2531.

34. Kochanska G, Murray KT, Harlan ET. Effortful control in early childhood: continuity and change, antecedents, and implications for social development. Dev Psychol. 2000;36(2):220.

35. Eggers K, De Nil LF, Bergh BRHV. den. Temperament dimensions in stuttering and typically developing children. J Fluen Disord. 2010 Dec;35(4):355-72.

36. Eichorn N, Pirutinsky S. Cognitive Flexibility and Effortful Control in School-Age Children With and Without Stuttering Disorders. J Speech Lang Hear Res. 2021 Mar 17;64(3):823-38.

37. Embrechts $M$, Ebben $H$, Franke P, Van De Poel C Temperament: A comparison between chidlren who stutter and children who do not stutter. In: Bosshardt HG, Yaruss JS, Peters HFM, editors.

Proceedings of the 3rd world congress on fluency disorders. Nybord, Denmark: Nimegan University Press.; 2000. p. 557-62.

38. Felsenfeld S, van Beijsterveldt CEM, Boomsma DI. Attentional regulation in young twins with probable stuttering, high nonfluency, and typical fluency. J Speech Lang Hear Res. 2010;53(5):114766.

39. Rocha MS, Yaruss JS, Rato JR. Temperament E, Functioning. and Anxiety in School-Age Children Who Stutter. Front Psychol [Internet]. 2019 Oct 4 [cited 2020 Apr 16];10. Available from: 
https://www.ncbi.nlm.nih.gov/pmc/articles/PMC6788391/.

40. Karrass J, Walden TA, Conture EG, Graham CG, Arnold HS, Hartfield KN, et al. Relation of emotional reactivity and regulation to childhood stuttering. J Commun Disord. 2006 Nov;39(6):402-23.

41. Anderson JD, Pellowski MW, Conture EG, Kelly EM. Temperamental characteristics of young children who stutter. J Speech Lang Hear Res. 2003;46(5):1221-33.

42. Howell P, Davis S, Patel H, Cuniffe P, Downing-Wilson D, Au-Yeung J, et al. Fluency development and temperament in fluent children and children who stutter. Theory, research and therapy in fluency disorders. 2004:250-6.

43. Ntourou K, Conture EG, Walden TA. Emotional reactivity and regulation in preschool-age children who stutter. J Fluen Disord. 2013 Sep;38(3):260-74.

44. Rothbart MK, Ahadi SA, Hershey KL, Fisher P. Investigations of temperament at three to seven years: The Children's Behavior Questionnaire. Child Dev. 2001 Oct;72(5):1394-408.

45. Rothbart MK, Sheese BE, Posner MI. Developing Mechanisms of Self-Regulation in Early Life. Emot Rev. 2011 Apr;1(2):207-13. 3(.

46. Chow HM, Chang S-E. White matter developmental trajectories associated with persistence and recovery of childhood stuttering: White Matter Development in Children Who Stutter. Hum Brain Mapp [Internet]. 2017 Apr [cited 2017 May 5]; Available from:

http://doi.wiley.com/10.1002/hbm.23590.

47. Chang S-E, Zhu DC. Neural network connectivity differences in children who stutter. Brain. 2013 Dec 1;136(12):3709-26.

48. Wiig EH, Secord WA, Semel EM. Clinical Evaluation of Language Fundamentals Preschool-2. San Antonio: Pearson; 2004.

49. Wiig EH, Semel EM, Secord WA. Clinical Evaluation of Language Fundamentals: Fifth Edition. San Antonio: Pearson; 2013.

50. Goldman R, Fristoe M. Goldman-Fristoe test of articulation - second edition. Circle Pines: American Guidance Service, Inc.; 2000.

51. Wechsler D. Manual for the Wechsler abbreviated intelligence scale (WASI). San Antonio TX Psychol Corp. 1999.

52. Wechsler D. Wechsler Pre-School and Primary Scale of Intelligence-Third. San Antonio: The Psychological Corporation; 2003.

53. Riley G. SSI-4 stuttering severity instrument fourth edition. Austin: Pro-Ed; 2009.

54. Ambrose NG, Yairi E. Normative disfluency data for early childhood stuttering. J Speech Lang Hear Res. 1999;42(4):895-909.

55. Theys C, Wouters J, Ghesquière P. Diffusion Tensor Imaging and Resting-State Functional MRIScanning in 5- and 6-Year-Old Children: Training Protocol and Motion Assessment. Schmitz C, editor. PLoS ONE. 2014 Apr 9;9(4):e94019. 
56. Power JD, Barnes KA, Snyder AZ, Schlaggar BL, Petersen SE. Spurious but systematic correlations in functional connectivity MRI networks arise from subject motion. Neurolmage. 2012 Feb 1;59(3):2142-54.

57. Conture EG, Kelly EM, Walden TA. Temperament. Speech and Language: An Overview. J Commun Disord. 2013;46(2):125-42.

58. Eggers K, Millard S, Kelman E. Temperament and the Impact of Stuttering in Children Aged 8-14 Years. J Speech Lang Hear Res. 2021 Feb 17;64(2):417-32.

59. Kefalianos E, Onslow M, Packman A, Vogel A, Pezic A, Mensah F, et al. The History of Stuttering by 7 Years of Age: Follow-Up of a Prospective Community Cohort. J Speech Lang Hear Res. 2017 Oct 17;60(10):2828.

60. Reilly S, Onslow M, Packman A, Cini E, Conway L, Ukoumunne OC, et al. Natural history of stuttering to 4 years of age: A prospective community-based study. Pediatrics. 2013;132:460-7.

61. Walsh B, Smith A, Christ SL, Weber C. Sympathetic Nervous System Activity in Preschoolers Who Stutter. Front Hum Neurosci [Internet]. 2019 [cited 2019 Dec 12];13. Available from: https://www.frontiersin.org/articles/10.3389/fnhum.2019.00356/full.

62. Alm PA. Stuttering in relation to anxiety, temperament, and personality: Review and analysis with focus on causality. J Fluen Disord. 2014 Jun;40:5-21.

63. Howell P. Assessment of Some Contemporary Theories of Stuttering That Apply to Spontaneous Speech. Contemp Issues Commun Sci Disord CICSD. 2004;31:122-39.

64. Viddal KR, Berg-Nielsen TS, Wan MW, Green J, Hygen BW, Wichstrøm L. Secure attachment promotes the development of effortful control in boys. Attach Hum Dev. 2015 May 4;17(3):319-35.

65. Else-quest NM, Hyde JS, Goldsmith HH, Hulle CAV. Gender differences in temperament: A metaanalysis. Psychol Bull. 2006;33-72.

66. Mutlu AK, Schneider M, Debbané M, Badoud D, Eliez S, Schaer M. Sex differences in thickness, and folding developments throughout the cortex. Neurolmage. 2013 Nov 15;82:200-7.

67. Posner MI, Rothbart MK, Sheese BE, Tang Y. The anterior cingulate gyrus and the mechanism of selfregulation. Cogn Affect Behav Neurosci. 2007 Dec;7(4)(1):391-5.

68. Coe JL, Micalizzi L, Josefson B, Parade SH, Seifer R, Tyrka AR. Sex differences in associations between early adversity, child temperament, and behavior problems. Int J Behav Dev. 2020 Nov 1;44(6):490-504.

69. Eisenberg N, Cumberland A, Spinrad TL, Fabes RA, Shepard SA, Reiser M, et al. The relations of regulation and emotionality to children's externalizing and internalizing problem behavior. Child Dev. 2001;72(4):1112-34.

70. Honomichl RD, Donnellan MB. Dimensions of Temperament in Preschoolers Predict Risk Taking and Externalizing Behaviors in Adolescents. Soc Psychol Personal Sci. 2012 Jan 1;3(1):14-22.

71. Stiegler LN, Davis R. Understanding Sound Sensitivity in Individuals with Autism Spectrum Disorders. Focus Autism Dev Disabil. 2010 Jun;25(2)(1):67-75. 
72. Barnea-Goraly N, Weinzimer SA, Ruedy KJ, Mauras N, Beck RW, Marzelli MJ, et al. High success rates of sedation-free brain MRI scanning in young children using simple subject preparation protocols with and without a commercial mock scanner-the Diabetes Research in Children Network (DirecNet) experience. Pediatr Radiol. 2014;44(2):181-6.

73. Carter AJ, Greer M-LC, Gray SE, Ware RS. Mock MRI: reducing the need for anaesthesia in children. Pediatr Radiol. 2010 Aug;40(8):1368-74.

74. de Bie HMA, Boersma M, Wattjes MP, Adriaanse S, Vermeulen RJ, Oostrom KJ, et al. Preparing children with a mock scanner training protocol results in high quality structural and functional MRI scans. Eur J Pediatr. 2010 Sep;169(9):1079-85.

75. Thieba C, Frayne A, Walton M, Mah A, Benischek A, Dewey D, et al. Time efficient preparation methods for MRI brain scanning in awake young children and factors associated with success. 2018 Feb 4 [cited 2018 Aug 9]; Available from: http://biorxiv.org/lookup/doi/10.1101/259358.

\section{Figures}

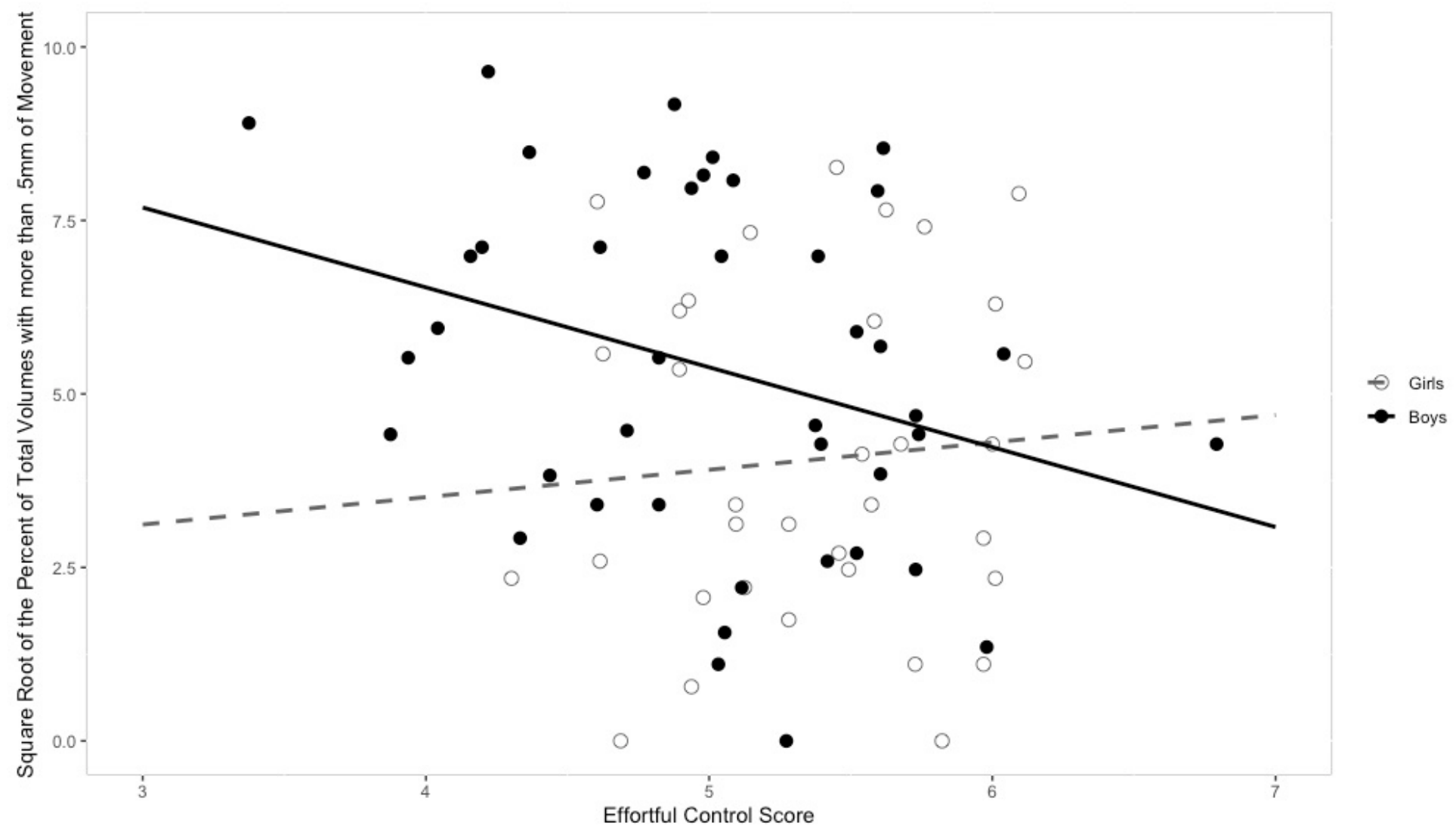

\section{Figure 1}

Sex differences in the relationship between effortful control and movement. For boys, effortful control was negatively correlated with movement. This relationship was not significant in girls. 


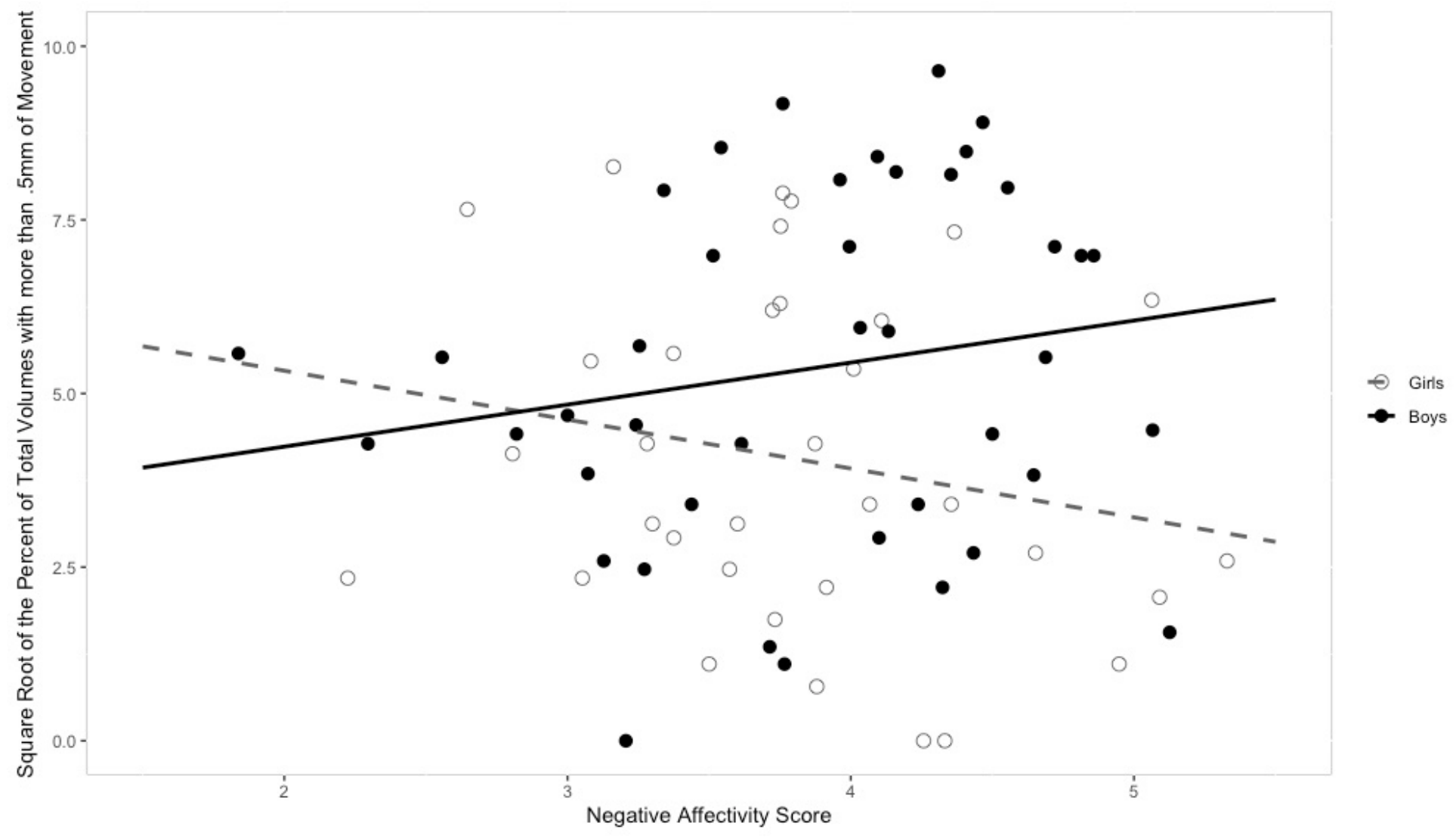

Figure 2

Sex differences in the relationship between negative affectivity and movement. While there was a significant interaction between negative affectivity and sex, follow-up sex specific regressions models showed that the relationship between negative affectivity scores and head movement were not significant in either sex. 